\title{
The Management of Atherosclerotic Renovascular Disease
}

\author{
Marcin Adamczak Andrzej Więcek \\ Department of Nephrology, Endocrinology and Metabolic Diseases, Medical University of Silesia, Katowice, Poland
}

\section{Key Words}

Renal artery stenosis · Angioplasty · Renovascular hypertension • Ischemic nephropathy

\begin{abstract}
Atherosclerotic renovascular disease (ARVD) seems to be a common clinical condition. ARVD is clinically presented as: 'silent' renal artery stenosis, renovascular hypertension, ischemic nephropathy leading to deterioration of renal function and recurrent 'flash' pulmonary edema. Management of ARVD involves both revascularization and medical treatment. However, the impact of revascularization on kidney function and blood pressure control is a matter of great controversy in view of the results of recent randomized clinical trials. At present, concerted medical management (includes lifestyle modifications, such as smoking cessation) remains the main treatment option for patients with ARVD. However, there is a need to accurately identify individuals who may benefit from renal revascularization.
\end{abstract}

Copyright $\odot 2011$ S. Karger AG, Basel

\section{Epidemiology and Natural History of Atherosclerotic Renovascular Disease}

Although no studies on the prevalence of renal artery stenosis (RAS) have been performed in the general population, atherosclerotic renovascular disease (ARVD) seems to be a common clinical condition. Recently Kalra et al. [1], using annual United States Medicare data, found that the diagnosis of ARVD in the period from 1992 to
2004 has increased threefold. In an autopsy series, Holley et al. [2] found RAS of $>50 \%$ in $56.4 \%$ of hypertensive patients and in $10.1 \%$ of normotensive subjects. Hansen et al. [3] using renal Doppler ultrasonography in a group of 870 elderly subjects (over age 65 years) found an RAS (stenosis $>60 \%$ ) in $6.8 \%$ of subjects. Angiographic prevalence studies have been performed only in patients who were undergoing angiography for coronary heart disease or peripheral arterial disease with a presumably higher risk of ARVD. RAS was found in $10.5-17.8 \%$ of patients undergoing diagnostic cardiac catheterization and in $25.3 \%$ of patients with peripheral artery disease [4]. A high (15-20\%) prevalence of RAS was reported in patients with arterial hypertension resistant to pharmacotherapy $[5,6]$, as well as in patients with arterial hypertension coexisting with type 2 diabetes mellitus [4]. Davis et al. [7] found an even higher RAS prevalence (32\%) in patients with grade III or IV hypertensive retinopathy. Moreover, RAS was found in $12-40 \%$ of those with chronic kidney disease (CKD) [4, 8, 9]. Kuczera et al. [5], in a retrospective analysis of 1,550 renal angiographies, found that age older than 60 years, ischemic heart disease, and a history of myocardial infarction or stroke significantly increased the RAS prevalence. On the other hand, in patients with an incidentally discovered RAS, hypertension and CKD were present in 65.5 and $27.5 \%$, respectively [4].

As ARVD is a progressive disease, deterioration of the kidney excretory function with potential CKD stage 5 necessitating renal replacement therapy is expected. Schreiber et al. [10] compared renal angiograms obtained a mean of 52 months apart in 85 patients who did not un-

\section{KARGER \\ Fax +4161306 1234 \\ E-Mail karger@karger.ch}

www.karger.com
(C) 2011 S. Karger AG, Basel

$1420-4096 / 11 / 0344-0277 \$ 38.00 / 0$

Accessible online at:

www.karger.com/kbr
Prof. Dr. hab. med. Andrzej Więcek, FRCP (Edin)

Department of Nephrology, Endocrinology and Metabolic Diseases

Medical University of Silesia, Katowice

Francuska Str. 20/24, PL-40-027 Katowice (Poland)

Tel. +48 32255 2695, E-Mail awiecek@spskm.katowice.pl 
dergo endovascular intervention. RAS had progressed in 37 of them (44\%), and the point of total occlusion was reached in 14 (16\%) patients. In contrast, in another study, progression in $11.1 \%$ of patients over 2.6 years was observed [11].

The worst prognosis was reported in patients with unilateral RAS and contralateral occlusion of renal artery. Among them, 44.7\% reached renal replacement therapy within 2 years of follow-up [12]. The highest occlusion rate occurs in patients with an atherosclerotic RAS of more than $60 \%$ (8\% in 3 years of follow-up) [13]. In addition, ARVD patients have a high risk of cardiovascular events [myocardial infarction, stroke, chronic heart failure (CHF) and sudden cardiac death] [14]. Only 5.1\% of ARVD patients are characterized by normal cardiac structure and function [15], and they are almost six times more likely to die than to reach CKD stage 5 [16]. Despite this, in an epidemiological study in the USA it was shown that ARVD was the primary cause of CKD stage 5 in $5.8 \%$ of cases [17]. The survival rate in patients with ARVD is linked to both baseline renal function and blood pressure control [14].

\section{Clinical Presentation of ARVD}

ARVD is clinically presented as: 'silent' RAS, renovascular hypertension, ischemic nephropathy and recurrent 'flash' pulmonary edema.

RAS is most often found in older patients [5], who are more likely to have essential hypertension and CKD due to other causes. It can be an incidental finding that is completely clinically 'silent'. A precise diagnosis of clinically 'silent' stenosis can be made only retrospectively in those patients with no improvement after revascularization.

Renovascular hypertension is defined as high blood pressure due to upregulation of neurohormonal activity in response to decreased perfusion caused by RAS. Again a precise diagnosis of renovascular hypertension can be made only retrospectively in those patients with improvement of blood pressure control and/or improvement of kidney function after revascularization.

Clinically relevant ischemic nephropathy can be defined as RAS with renal dysfunction not attributable to other causes. In the early stages, renal hypoxia plays a crucial role in the pathogenesis of ischemic nephropathy [18]. In the later stages, tubulointerstitial fibrosis occurs and, by impairment of regional blood flow, induces further ischemic injury [19]. Recently, in a histopathological study of 62 kidneys of patients with RAS who had undergone nephrectomy of a small kidney due to uncontrolled
Table 1. Indications (pro) and contraindications (contra) for endovascular revascularization in patients with atherosclerotic RAS

\begin{tabular}{ll}
\hline Pro & Contra \\
\hline $\begin{array}{l}\text { Refractory hypertension } \\
\text { 'Flash' pulmonary edema }\end{array}$ & $\begin{array}{l}\text { Normotension and normal } \\
\text { renal function }\end{array}$ \\
Unilateral RAS of a single kidney & $\begin{array}{l}\text { Contralateral renal artery } \\
\text { without RAS }\end{array}$ \\
Bilateral RAS & Negative captopril scintigraphy \\
Normal kidney size or $>8.0 \mathrm{~cm}$ & Small kidney size $(<8.0 \mathrm{~cm})$ \\
Intrarenal resistance $<0.8$ & Intrarenal resistance $>0.8$ \\
Long expected survival time & Short expected survival time \\
& \\
\hline
\end{tabular}

hypertension, it was found that the predominant pattern of injury was tubulointerstitial atrophy with mild global glomerulosclerosis [19]. The exact prevalence of ischemic nephropathy is unknown. In one study of patients with CKD, renal vascular lesions have often been detected (from $3.2 \%$ of patients under age 59 to $25 \%$ of those above age 70) [20]. Surveys of subjects who were on hemodialysis indicate that renal vascular disease is now more commonly assigned as the cause of CKD stage $5 \mathrm{~d}$ [21].

Recurrent 'flash' pulmonary edema is a less common ARVD presentation. It usually occurs in patients with critical bilateral RAS or significant unilateral stenosis of the artery supplying a solitary functioning kidney. Most of such patients are characterized by severe hypertension resistant to antihypertensive therapy and progression of CKD [22-24].

\section{Who Will Not Benefit from Revascularization in ARVD?}

Revascularization is typically not indicated in the following clinical situations: (a) in patients with normotension and normal kidney function (i.e. in clinically 'silent' RAS) or normal blood pressure obtained with antihypertensive therapy, (b) when a stenosed renal artery is supplying a small cirrhotic kidney (longitudinal diameter less than $8.0 \mathrm{~cm}$ in an adult patient), and (c) in patients with high intrarenal resistance assessed by Doppler sonography (intrarenal resistance higher than 0.8) corresponding to advanced kidney fibrosis due to chronic ischemic nephropathy [25] (table 1). The heterogeneity in outcomes after renal revascularization undoubtedly reflects the effects of preexisting irreversible chronic renal parenchymal damage. Unfortunately, there are no reliable tools to diag- 
nose irreversible ischemia in the kidney. The predictive value of increased intrarenal resistance is not unanimously accepted [26]. The captopril renal scan seems to have that capability but is not accurate in patients with bilateral RAS or in patients with a glomerular filtration rate (GFR) of less than $50 \mathrm{ml} / \mathrm{min}$. However, it should be mentioned that some novel technologies namely blood-oxygen-leveldependent magnetic resonance imaging are being investigated for such a role [27]. Blood-oxygen-level-dependent imaging involves 'labeling' of deoxyhemoglobin (a paramagnetic compound) allowing analysis of patterns of regional tissue oxygenation in ARVD kidneys [27].

\section{Blood Pressure Control and Prevention of CKD Progression as Indications for Intervention in ARVD}

During the last 50 years, ARVD was treated by surgical revascularization [28]. In 1978, endovascular therapy became implemented for kidney revascularization [29]. Initially it was balloon angioplasty and more recently balloon angioplasty with stent insertion [30]. Most ARVD lesions are located in the ostium and many are extensions of calcified aortic plaque. These hard lesions tend to rebound to their original shape after angioplasty alone. Stent insertion provides the additional force necessary to permanently disrupt the lesion, leading to a longer-lasting result. Stent insertion in atherosclerotic RAS has improved the procedural efficacy of endovascular therapy by up to $98 \%$ (from 46 to $77 \%$ ), overcoming the problem of elastic recoil or artery dissection and reduced the risk of restenosis (defined as over 50\%) within 6-9 months from $26-48$ to $17 \%$ [31]. Currently there is no evidence suggesting that drug-eluting stents will further reduce the risk of renal artery restenosis.

A series of cases with spectacular improvement of the kidney function in patients with ARVD and management of concomitant arterial hypertension was documented [32]. However, the impact of revascularization on kidney function and blood pressure control still remains a matter of controversy in view of the results of recent randomized trials [33]. In patients with unilateral RAS, when blood pressure is well controlled with medical treatment alone and the kidney function is stable during several months, renal revascularization may not offer any significant improvement.

Until 2009, there were only 3 randomized clinical trials comparing angioplasty and intervention restricted to the pharmacological management (Scottish and New Castle [34], EMMA [35] and DRASTIC study [36]). These
3 trials recruited 210 patients. One hundred and four of those were randomized to percutaneous angioplasty, 106 received only pharmacological therapy and only 2 received a stent. A meta-analysis of data from these trials revealed no clear benefit for angioplasty at the 6-month follow-up [37]. There was a greater reduction of systolic blood pressure (by $6.3 \mathrm{~mm} \mathrm{Hg}$; 95\% CI 0.8-11.7; p = 0.02) and diastolic blood pressure (by $3.3 \mathrm{~mm} \mathrm{Hg}$; $95 \%$ CI $0.4-$ $6.2 ; \mathrm{p}=0.03)$. At 6 months after angioplasty, the serum creatinine concentration was lower by $9.7 \mu \mathrm{mol} / \mathrm{l}$ (95\% CI $0.7-18.7 ; \mathrm{p}=0.03)$. Results of this meta-analysis confirmed that in general angioplasty is not related to the great benefit of kidney function and blood pressure control [37]. The recently published meta-analysis of 11 trials with stent insertion showed that there is no clinical characteristic that reliably predicts the effect of renal angioplasty on clinical outcomes like renal function improvement and/or blood pressure reduction [38]. High baseline pulse pressure predicts smaller decreases in systolic blood pressure after intervention and high pretreatment diastolic blood pressure is the predictor of a larger diastolic blood pressure reduction [38].

In 2009, results of 2 randomized clinical trials were published comparing angioplasty and stenting with medical therapy alone (STAR and ASTRAL) $[39,40]$. The aim of the multicenter (10 centers in Europe), randomized, unblinded STAR study (stent placement and blood pressure and lipid-lowering for the prevention of progression of renal dysfunction caused by atherosclerotic ostial stenosis of the renal artery) was to assess the efficacy and safety of stent placement in patients with ARVD and impaired renal function [estimated GFR (eGFR) $<80 \mathrm{ml} / \mathrm{min}$ ]. One hundred and forty patients with ostial RAS $\geq 50 \%$ were randomly allocated to endovascular intervention plus medical therapy or medical therapy alone and followed up for 2 years. The primary endpoint was a $>20 \%$ decrease in eGFR. The number of patients obtaining this primary endpoint, blood pressure control, cardiovascular morbidity and mortality were similar in both groups. Endovascular intervention in the STAR study resulted in several serious procedure-related complications, including 2 procedure-related deaths (3\%), 1 late death secondary to an infected hematoma and 1 patient who required dialysis secondary to cholesterol embolism. Results of the STAR study revealed no benefit of revascularization over pharmacological treatment alone for kidney function [39].

To overcome the weakness of previous trials, the ASTRAL (angioplasty and stenting for renal artery lesions) Collaborative Group designed the largest study to date [40]. The aim of this multicenter, randomized, unblinded 
Table 2. Indications and evidence for endovascular revascularization

\begin{tabular}{ll}
\hline Indication & Evidence \\
\hline $\begin{array}{l}\text { Patients resistant to antihypertensive therapy (hypertension despite } \\
\text { at least } 3 \text { antihypertensive medications at maximal doses, one of them } \\
\text { being a diuretic, chosen according to the GFR) }\end{array}$ & $\begin{array}{l}\text { Subgroup analysis of randomized } \\
\text { controlled trial (DRASTIC) [36] }\end{array}$ \\
\hline $\begin{array}{l}\text { Patients with recurrent episodes of congestive heart failure without an } \\
\text { obvious cardiac cause (i.e. 'flash' pulmonary edema) }\end{array}$ & Retrospective studies [22-24, 46] \\
\hline $\begin{array}{l}\text { Patients whose renal function is rapidly declining with bilateral RAS or } \\
\text { stenosis to a single functioning kidney, without another obvious cause }\end{array}$ & Prospective cohort study [45] \\
\hline
\end{tabular}

study was to determine whether revascularization together with medical therapy improves renal function and other outcomes, compared to medical therapy alone in patients with ARVD.

In the ASTRAL study, 806 patients were enrolled (i.e. six times more than in the STAR study) from 54 medical centers in the UK and 4 in Australia and New Zealand. Patients were only included in this study if physicians were uncertain whether or not early revascularization is indicated [40]. However, the treatment of ARVD is so controversial that different physicians cannot agree on the most effective treatment strategy for a particular patient. Therefore, such clinical inclusion and exclusion criteria are incomprehensible and potentially introduce considerable selection bias into the trial design. As a consequence, numerous patients with critical lesions but without a small kidney and severe arterial hypertension (this is a group of patients that presumably benefits the most from revascularization) were left out of the study. The primary goal of the ASTRAL study was to assess the change in renal function by measuring the mean slope of the reciprocal of the serum creatinine concentration over time. Secondary goals were to assess blood pressure, the time to the first renal event (acute kidney injury, renal replacement therapy, nephrectomy or death from renal failure) and the time to the first major cardiovascular event and mortality. The mean degree of RAS was $76 \%$, and $59 \%$ of patients had a $\geq 70 \%$ degree of stenosis. The majority of patients had a significant impairment of kidney function (60\% of patients had a serum creatinine concentration above $150 \mu \mathrm{mol} / \mathrm{l}$; patients in the endovascular intervention plus medical therapy group and in the medical therapy alone group had a mean creatinine concentration of 179 and $178 \mu \mathrm{mol} / \mathrm{l}$ and a mean eGFR of 40.3 and $39.8 \mathrm{ml} / \mathrm{min}$, respectively). Additionally, at baseline, blood pressure was significantly elevated (mean val- ues were 149/76 and 152/76 mm Hg in endovascular intervention plus medical therapy and medical therapy alone groups, respectively).

All patients were randomly allocated to endovascular intervention plus medical therapy or medical therapy alone. The median follow-up was 34 months. The majority $(95 \%)$ of patients who underwent revascularization received a stent, and the technical success was noted in 95\% of these procedures. A total of 31 serious complications of revascularization occurred in 23 out of 335 patients (6.7\%).

In both groups, the serum creatinine concentration was slowly rising. There were no significant differences in the kidney function in the entire studied group and in any of the subgroups defined according to serum creatinine concentration, eGFR, severity of RAS and kidney length. During the study, blood pressure was slightly and slowly declining over time in both groups. After 5 years, the average systolic blood pressure was lower by $5 \mathrm{~mm} \mathrm{Hg}$, while the diastolic blood pressure was $2 \mathrm{~mm} \mathrm{Hg}$ lower, and this was similar in both groups. There was no difference between the two studied groups with respect to the time to the first renal event, the time to the first major cardiovascular event and mortality (survival: $60 \%$ in the revascularization group vs. $57 \%$ in the pharmacological treatment alone group). Results of the ASTRAL study revealed no benefits of revascularization over pharmacological treatment alone in patients with atherosclerotic RAS [40].

The data of the ASTRAL study are somehow discouraging and do not allow generalized conclusions. This study only demonstrates the lack of benefits for revascularization in ARVD patients in whom clinicians were 'uncertain' whether or not to perform revascularization.

Similarly to STAR, endovascular intervention in the ASTRAL study resulted in several serious procedure-related complications. In this study, the major adverse event 
rate in the first $24 \mathrm{~h}$ was $9 \%$. Of the 280 patients in the revascularization group for whom data on adverse events were available at 1 month, 55 (20\%) suffered from a serious adverse event (including 2 patients who died). Since such interventions are associated with substantial morbidity, inconvenience and costs, without visible clinical benefits the widespread use of these procedures is questioned.

On the other hand, the ASTRAL study does not exclude eventual subgroups that might benefit from endovascular revascularization, i.e. patients with refractory hypertension, flush pulmonary edema or whose renal function has been rapidly declining.

The next larger study addressing the same issue, the CORAL (cardiovascular outcome in renal atherosclerotic lesions) trial, funded by the National Institutes of Health, is currently ongoing [41]. The study population seems to be better defined as compared with ASTRAL, with respect to the degree of RAS (greater than 60\%). Inclusion criteria are a documented history of hypertension, taking 2 or more antihypertensive drugs or CKD stage 3 or greater and stenosis of $60 \%$ or greater but less than $100 \%$. The primary endpoint is survival free of cardiovascular and renal adverse events, defined as a composite of cardiovascular or renal death, stroke, myocardial infarction, hospitalization for congestive heart failure, progressive renal insufficiency, or need for permanent renal replacement therapy. The CORAL study is scheduled to be completed in 2011. The larger number of participants $(\mathrm{n}=$ $1,080)$ may offer stronger conclusions, especially in pool analysis together with the ASTRAL study [41].

\section{Are There Patients Who May Benefit from Endovascular Intervention in ARVD?}

From the above-mentioned results one can conclude that, in an unselected population with atherosclerotic RAS, angioplasty and stent insertion provides no benefits to the blood pressure control and renal function in comparison to medical therapy only. However, in view of some clinical observations (nonrandomized studies), one may expect that patients with declining renal function, $\mathrm{CHF}$ and with 'flash' pulmonary edema may benefit from endovascular intervention in ARVD.

In several case series, patients whose renal function had been declining before intervention had impressive rates of better renal function afterward [42-44]. Muray et al. [45] found in a prospective cohort study that a rise in serum creatinine before intervention seems to predict an improvement in renal function after revascularization.
Kane et al. [46] showed in a group of 163 patients with significant $(>70 \%)$ ARVD that both ARVD and CHF were present in $31 \%$. They also compared 50 revascularized RAS CHF patients with the ones medically treated alone in a case-control study. During the follow-up period, patients who underwent revascularization due to atherosclerotic RAS had better blood pressure (systolic blood pressure decrease by 28 vs. $9 \mathrm{~mm} \mathrm{Hg}$ ) and heart failure control, with a fivefold reduction in hospitalizations and lower NYHA class (1.9 vs. 2.6) when compared with patients who received medical treatment alone [46].

Stent insertion usually improves 'flash' pulmonary edema [22-24]. Acute pulmonary edema in patients with bilateral RAS seems to be a unique case in which improvement in clinical status can be expected in most patients after endovascular intervention. Blood pressure improves in $94-100 \%$ of such patients $[22,47]$ and renal function either improves or stabilizes in $77-91 \%$ of cases [22-24, 47]. It is also important to stress that pulmonary edema resolves without recurrence in $77-100 \%$ of such patients [22-24].

\section{Current Recommendations concerning the Management in Patients with ARVD}

ESH/ESC guidelines from 2007 do not recommend renal revascularization if the kidney function is preserved, blood pressure is well controlled, RAS is not tight and there is a history of hypertension longer than 10 years [48]. Management in patients with this type of arterial hypertension is not mentioned in the reappraisal of European guidelines on hypertension management in a document from the European Society of Hypertension Task Force, published at the end of 2009 [49].

Before the results of the CORAL trial become published, it seems reasonable to recommend that the intervention in ARVD should be restricted to: (a) patients with recurrent episodes of CHF without an obvious cardiac cause and with bilateral RAS or stenosis to a single functioning kidney; (b) patients whose renal function is rapidly declining over the past 3-6 months with bilateral RAS or stenosis to a single functioning kidney, without another obvious cause; (c) patients with arterial hypertension resistant to medical therapy (hypertension despite at least 3 antihypertensive medications at maximal doses, one of them being a diuretic, chosen according to the GFR). Such recommendations are in line with the American College of Cardiology/American Heart Association guidelines [50]. 
At present, concerted medical management (includes lifestyle modifications - among others smoking cessation, multiple antihypertensive drugs - thiazide diuretics, calcium antagonists and/or renin-angiotensin system blockers - except in the presence of bilateral RAS, statins, low-dose aspirin and adequate carbohydrate metabolism control monitored with $\mathrm{Hb}_{1} \mathrm{Ac}$ blood levels in diabetic subjects) remains the main treatment for all ARVD patients [48]. There is also a great need to accurately iden- tify those individuals with ARVD who will derive clinical benefit from renal revascularization. We can only express our hope that it will be possible after the publication of the results from the CORAL study [41].

\section{Disclosure Statement}

No conflict of interest.

\section{References}

1 Kalra PA, Guo H, Gilbertson DT, Liu J, Chen SC, Ishani A, Collins AJ, Foley RN: Atherosclerotic renovascular disease in the United States. Kidney Int 2010;77:37-43.

-2 Holley KE, Hunt JC, Brown AL Jr, Kincaid OW, Sheps SG: Renal artery stenosis. A clinical-pathologic study in normotensive and hypertensive patients. Am J Med 1964;37: 14-22.

-3 Hansen KJ, Edwards MS, Craven TE, Cherr GS, Jackson SA, Appel RG, Burke GL, Dean $\mathrm{RH}$ : Prevalence of renovascular disease in the elderly: a population-based study. J Vasc Surg 2002;36:443-451.

4 de Mast Q, Beutler JJ: The prevalence of atherosclerotic renal artery stenosis in risk groups: a systemic literature review. J Hypertens 2009;27:1333-1340.

5 Kuczera P, Włoszczyńska E, Adamczak M, Pencak P, Chudek J, Więcek A: Frequency of renal artery stenosis and variants of renal vascularization in hypertensive patients: analysis of 1,550 angiographies in one centre. J Hum Hypertens 2009;23:396-401.

6 6 van Jaarsveld BC, Krijnen P, Derkx FH, Deinum J, Woittiez AJ, Postma CT, Schalekamp M: Resistance to antihypertensive medication as predictor of renal artery stenosis comparison of two drug regimens. J Hum Hypertens 2001;15:669-676.

7 Davis BA, Crook JE, Vestal RE, Oates JA: Prevalence of renovascular hypertension in patients with grade III or IV hypertensive retinopathy. N Engl J Med 1979;301:1273-1276.

8 van Ampting JM, Penne EL, Beek FJ, Koomans HA, Boer WH, Beutler JJ: Prevalence of atherosclerotic renal artery stenosis in patients starting dialysis. Nephrol Dial Transplant 2003;18:1147-1151.

$\checkmark$ Coen G, Calabria S, Lai S, Moscaritolo E, Nofroni I, Ronga G, Rossi M, Ventroni G, Sardella D, Ferrannini M, Zaccaria A, Cianci R: Atherosclerotic ischemic renal disease. Diagnosis and prevalence in an hypertensive and/or uremic elderly population. BMC Nephrol 2003;4:2.

10 Schreiber MJ, Pohl MA, Novick AC: The natural history of atherosclerotic and fibrous renal artery disease. Urol Clin North Am 1984; 11:383-392.
11 Crowley JJ, Santos RM, Peter RH, Puma JA, Schwab SJ, Phillips HR, Stack RS, Conlon PJ: Progression of renal artery stenosis in patients undergoing cardiac catheterization. Am Heart J 1998;136:913-918.

12 Connolly JO, Higgins RM, Walters HL, Mackie AD, Drury PL, Hendry BM, Scoble JE: Presentation, clinical features and outcome in different patterns of atherosclerotic renovascular disease. QJM 1994;87:413-421.

13 Zierler RE, Bergelin RO, Davidson RC, Cantwell-Gab K, Polissar NL, Strandness DE Jr: A prospective study of disease progression in patients with atherosclerotic renal artery stenosis. Am J Hypertens 1996;9: 1055-1061.

14 Wright JR, Shurrab AE, Cheung C, Waldek S, O’Donoghue DJ, Foley RN, Mamtora H, Kalra PA: A prospective study of the determinants of renal functional outcome and mortality in atherosclerotic renovascular disease. Am J Kidney Dis 2002;39:1153-1161.

-15 Wright JR, Shurrab AE, Cooper A, Kalra PR, Foley RN, Kalra PA: Left ventricular morphology and function in patients with atherosclerotic renovascular disease. J Am Soc Nephrol 2005;16:2746-2753.

16 Kalra PA, Guo H, Kausz AT, Gilbertson DT, Liu J, Chen SC, Ishani A, Collins AJ, Foley $\mathrm{RN}$ : Atherosclerotic renovascular disease in United States patients aged 67 years or older: risk factors, revascularization, and prognosis. Kidney Int 2005;68:293-301.

17 Guo H, Kalra PA, Gilbertson DT, Liu J, Chen SC, Collins AJ, Foley RN: Atherosclerotic renovascular disease in older US patients starting dialysis, 1996 to 2001. Circulation 2007; 115:50-58.

18 Nangaku M: Chronic hypoxia and tubulointerstitial injury: a final common pathway to end-stage renal failure. J Am Soc Nephrol 2006;17:17-25.

19 Keddis MT, Garovic VD, Bailey KR, Wood CM, Raissian Y, Grande JP: Ischaemic nephropathy secondary to atherosclerotic renal artery stenosis: clinical and histopathological correlates. Nephrol Dial Transplant 2010;25:3615-3622.
20 Coen G, Manni M, Giannoni MF, Bianchini G, Calabria S, Mantella D, Pigorini F, Taggi F: Ischemic nephropathy in an elderly nephrologic and hypertensive population. Am J Nephrol 1998;18:221-227.

21 Fatica RA, Port FK, Young EW: Incidence trends and mortality in end-stage renal disease attributed to renovascular disease in the United States. Am J Kidney Dis 2001;37: 1184-1190.

22 Messina LM, Zelenock GB, Yao KA, Stanley JC: Renal revascularization for recurrent pulmonary edema in patients with poorly controlled hypertension and renal insufficiency: a distinct subgroup of patients with arteriosclerotic renal artery occlusive disease. J Vasc Surg 1992;15:73-80.

23 Bloch MJ, Trost DW, Pickering TG, Sos TA, August P: Prevention of recurrent pulmonary edema in patients with bilateral renovascular disease through renal artery stent placement. Am J Hypertens 1999;12:1-7.

24 Gray BH, Olin JW, Childs MB, Sullivan TM, Bacharach JM: Clinical benefit of renal artery angioplasty with stenting for the control of recurrent and refractory congestive heart failure. Vasc Med 2002;7:275-279.

25 Radermacher J, Chavan A, Bleck J, Vitzthum A, Stoess B, Gebel MJ, Galanski M, Koch KM, Haller H: Use of Doppler ultrasonography to predict the outcome of therapy for renal-artery stenosis. N Engl J Med 2001;344: 410-417.

26 García-Criado A, Gilabert R, Nicolau C, Real MI, Muntañá X, Blasco J, Ganau S, Brú C: Value of Doppler sonography for predicting clinical outcome after renal artery revascularization in atherosclerotic renal artery stenosis. J Ultrasound Med 2005;24:1641-1647.

27 Gloviczki ML, Glockner JF, Lerman LO, McKusick MA, Misra S, Grande JP, Textor SC: Preserved oxygenation despite reduced blood flow in poststenotic kidneys in human atherosclerotic renal artery stenosis. Hypertension 2010;55:961-966.

28 Katz YJ, Hannon DW, Baronofsky ID: Studies on kidney revascularization: renal function following revascularization and bilateral renal artery transection. Surgery 1956; 40:140-146. 
-29 Grüntzig A, Kuhlmann U, Vetter W, Lütolf U, Meier B, Siegenthaler W: Treatment of renovascular hypertension with percutaneous transluminal dilatation of a renal-artery stenosis. Lancet 1978;i:801-802.

- 30 Joffre F, Bernadet P, Rousseau H, Nomblot C, Durand D, Chamontin B, Suc JM: Usefulness of a percutaneous endoprosthesis in the treatment of renal artery stenoses. Arch Mal Coeur Vaiss 1989;82:1199-1204.

- 31 Leertouwer TC, Gussenhoven EJ, Bosch JL, van Jaarsveld BC, van Dijk LC, Deinum J, Man In 't Veld AJ: Stent placement for renal arterial stenosis: where do we stand? A metaanalysis. Radiology 2000;216:78-85.

32 Bell GM, Reid J, Buist TA: Percutaneous transluminal angioplasty improves blood pressure and renal function in renovascular hypertension. Q J Med 1987;63:393-403

33 Więcek A, Chudek J, Adamczak M: Indications for renal revascularization - The landscape after the ASTRAL study. Nephrol Dial Transplant 2010;25:2399-2402.

34 Webster J, Marshall F, Abdalla M, Dominiczak A, Edwards R, Isles CG, Loose H, Main J, Padfield P, Russell IT, Walker B, Watson M, Wilkinson R: Randomised comparison of percutaneous angioplasty vs continued medical therapy for hypertensive patients with atheromatous renal artery stenosis. Scottish and Newcastle Renal Artery Stenosis Collaborative Group. J Hum Hypertens 1998;12:329-335.

- 35 Plouin PF, Chatellier G, Darné B, Raynaud A: Blood pressure outcome of angioplasty in atherosclerotic renal artery stenosis: a randomized trial. Essai Multicentrique Medicaments versus Angioplastie (EMMA) Study Group. Hypertension 1998;31:823-829.

- 36 van Jaarsveld BC, Krijnen P, Pieterman H, Derrkx FH, Deinum J, Postma CT, Dees A, Woittiez AJ, Bartelink AK, Man in 't Veld AJ, Schalekamp MA: The effect of balloon angioplasty on hypertension in atherosclerotic renal-artery stenosis. Dutch Renal Artery Stenosis Intervention Cooperative Study Group. N Engl J Med 2000;342:1007-1014.

- 37 Ives NJ, Wheatley K, Stowe RL, Krijnen P, Plouin PF, van Jaarsveld BC, Gray R: Continuing uncertainty about the value of percutaneous revascularization in atherosclerotic renovascular disease: a meta-analysis of randomized trials. Nephrol Dial Transplant 2003;18:298-304.

- 38 Ronden RA, Houben AJ, Kessels AG, Stehouwer CD, de Leeuw PW, Kroon AA: Predictors of clinical outcome after stent placement in atherosclerotic renal artery stenosis: a systematic review and meta-analysis of prospective studies. J Hypertens 2010;28:23702377.

-39 Bax L, Woittiez AJ, Kouwenberg HJ, Mali WP, Buskens E, Beek FJ, Braam B, Huysmans
FT, Schultze Kool LJ, Rutten MJ, Doorenbos CJ, Aarts JC, Rabelink TJ, Plouin PF, Raynaud A, van Montfrans GA, Reekers JA, van den Meiracker AH, Pattynama PM, van de Ven PJ, Vroegindeweij D, Kroon AA, de Haan MW, Postma CT, Beutler JJ: Stent placement in patients with atherosclerotic renal artery stenosis and impaired renal function: a randomized trial. Ann Intern Med 2009;150:840-848.

40 The ASTRAL Investigators: Revascularization versus medical therapy for renal-artery stenosis. N Engl J Med 2009;361:1953-1962.

-41 Cooper CJ, Murphy TP, Matsumoto A Steffes M, Cohen DJ, Jaff M, Kuntz R, Jamerson K, Reid D, Rosenfield K, RundbackJ, D’Agostino R, Henrich W, Dworkin L: Stent revascularization for the prevention of cardiovascular and renal events among patients with renal artery stenosis and systolic hypertension: rationale and design of the CORAL trial. Am Heart J 2006;152:59-66.

-42 Beutler JJ, Van Ampting JM, Van De Ven PJ, Koomans HA, Beek FJ, Woittiez AJ, Mali WP: Long-term effects of arterial stenting on kidney function for patients with ostial atherosclerotic renal artery stenosis and renal insufficiency. J Am Soc Nephrol 2001;12: 1475-1481.

-43 Zeller T, Frank U, Müller C, Bürgelin K, Sinn L, Bestehorn HP, Cook-Bruns N, Neumann FJ: Predictors of improved renal function after percutaneous stent-supported angioplasty of severe atherosclerotic ostial renal artery stenosis. Circulation 2003;108:2244-2249.

44 Paraskevas KI, Perrea D, Briana DD, Liapis $\mathrm{CD}$ : Management of atherosclerotic renovascular disease: the effect of renal artery stenting on renal function and blood pressure. Int Urol Nephrol 2006;38:683-691.

45 Muray S, Martın M, Amoedo ML, García C, Jornet AR, Vera M, Oliveras A, Gómez X, Craver L, Real MI, García L, Botey A, Montanyà $\mathrm{X}$, Fernández E: Rapid decline in renal function reflects reversibility and predicts the outcome after angioplasty in renal artery stenosis. Am J Kidney Dis 2002;39:60-66.

46 Kane GC, Xu N, Mistrik E, Stanson AW, Garovic VD: Renal artery revascularization improves heart failure control in patients with atherosclerotic renal artery stenosis. Nephrol Dial Transplant 2010;25:813-820.

47 Pickering TG, Herman L, Devereux RB, Sotelo JE, James GD, Sos TA, Silane MF, Laragh $\mathrm{JH}$ : Recurrent pulmonary oedema in hypertension due to bilateral renal artery stenosis: treatment by angioplasty or surgical revascularisation. Lancet 1988;ii:551-552.

48 Mancia G, De Backer G, Dominiczak A, Cifkova R, Fagard R, Germano G, Grassi G, Heagerty AM, Kjeldsen SE, Laurent S, Narkiewicz K, Ruilope L, Rynkiewicz A, Schmieder RE, Boudier HA, Zanchetti A, et al, ESH-
ESC Task Force on the Management of Arterial Hypertension: 2007 Guidelines for the management of arterial hypertension: the Task Force for the management of arterial hypertension of the European Society of Hypertension (ESH) and of the European Society of Cardiology (ESC). J Hypertens 2007; 25:1105-1187.

49 Mancia G, Laurent S, Agabiti Rosei E, Ambrosioni E, Burnier M, Caulfield MJ, Cifkova R, Clément D, Coca A, Dominiczak A, Erdine S, Fagard R, Farsang C, Grassi G, Haller $\mathrm{H}$, Heagerty A, Kjeldsen SE, Kiowski W, Mallion JM, Manolis A, Narkiewicz K, Nilsson P, Olsen MH, Rahn KH, Redon J, Rodicio J, Ruilope L, Schmieder RE, Struijker-Boudier HA, van Zwieten PA, Viigimaa M, Zanchetti A, European Society of Hypertension: Reappraisal of European guidelines on hypertension management: a European Society of Hypertension Task Force document. J Hypertens 2009;27:2121-2158.

50 Hirsch AT, Haskal ZJ, Hertzer NR, Bakal CW, Creager MA, Halperin JL, Hiratzka LF, Murphy WR, Olin JW, Puschett JB, Rosenfield KA, Sacks D, Stanley JC, Taylor LM Jr, White CJ, White J, White RA, Antman EM, Smith SC Jr, Adams CD, Anderson JL, Faxon DP, Fuster V, Gibbons RJ, Hunt SA, Jacobs AK, Nishimura R, Ornato JP, Page RL, Riegel B, American Association for Vascular Surgery; Society for Vascular Surgery; Society for Cardiovascular Angiography and Interventions; Society for Vascular Medicine and Biology; Society of Interventional Radiology; ACC/AHA Task Force on Practice Guidelines Writing Committee to Develop Guidelines for the Management of Patients With Peripheral Arterial Disease; American Association of Cardiovascular and Pulmonary Rehabilitation; National Heart, Lung, and Blood Institute; Society for Vascular Nursing; TransAtlantic Inter-Society Consensus; Vascular Disease Foundation: ACC/AHA 2005 Practice Guidelines for the management of patients with peripheral arterial disease (lower extremity, renal, mesenteric, and abdominal aortic): a collaborative report from the American Association for Vascular Surgery/Society for Vascular Surgery, Society for Cardiovascular Angiography and Interventions, Society for Vascular Medicine and Biology, Society of Interventional Radiology, and the ACC/AHA Task Force on Practice Guidelines (Writing Committee to Develop Guidelines for the Management of Patients With Peripheral Arterial Disease): endorsed by the American Association of Cardiovascular and Pulmonary Rehabilitation; National Heart, Lung, and Blood Institute; Society for Vascular Nursing; TransAtlantic InterSociety Consensus; and Vascular Disease Foundation. Circulation 2006;113:e463e654. 